\title{
INFLUENCE OF SELECTED CUTTING CONDITIONS ON CUTTING FORCES
}

\author{
Augustín Görög', Dana Stančeková2, Mária Kapustová', Ingrid Görögová', Izabela Miturska³ \\ 1 Slovak University of Technology, Faculty of Material Science and Technology, J. Bottu 25, 917 24, Trnava, \\ Slovak Republic, e-mail: augustin.gorog@stuba.sk, maria.kapustova@stuba.sk, ingrid.gorogova@stuba.sk \\ 2 University of Žilina, Faculty of Mechanical Engineering, Univerzitna 1, 010 26, Žilina, Slovak Republic, e-mail: \\ dana.stancekova@fstroj.uniza.sk \\ ${ }^{3}$ Faculty of Mechanical Engineering, Lublin University of Technology, Nadbystrzycka 36, 20-618 Lublin, Poland
}

Received: 2016.12 .15

Accepted: 2017.02.01

Published: 2017.03.01

\begin{abstract}
The article presents achieved results of research focused on the influence of various factors modification on cutting forces at longitudinal turning of steel C 45 using two tools with different shape and geometry at constant values of feed and depth of cut. The individual components of cutting force were compared reciprocally, i. e. axial, radial, tangential and finally resulting cutting force depending on cutting speed.
\end{abstract}

Keywords: machining, cutting forces, cutting speed, dynamometer.

\section{INTRODUCTION}

Knowledge of size and direction of cutting forces as well as the knowledge of their modification with regard to the variation of process parameters is essential for evaluation and optimization of cutting process from the perspective of performance, quality and economy. The cutting forces are important indicators of the cutting process course and help understand the machining processes and their respective actions $[1,2]$.

Comprehension and knowledge of cutting process relations with regard to cutting forces enables not only to optimize the particular process parameters successfully but also to prevent critical situations in the area of work safety. For some specific workpieces (i.e. parts made of brittle materials or with thin walls susceptible to crack initiation, etc.) especially the cutting forces are limiting factor for application of particular technology type [3, 4].

Dynamic strain of a system machine - tool - workpiece - fixture caused by cutting forces has also essential impact on stability of cutting process and thereby on workpiece accuracy and quality (integrity) of machined surface. In terms of energy, the cutting force is one of the most sensitive indicators of machining power $[5,6]$.
Information on cutting force size and its behaviour during the cutting process enables to perform the final economic optimization analyses of production processes, technologies, and selection of cutting tools, working machines and cutting conditions $[7,8]$.

\section{EXPERIMENT CONDITIONS}

In order to perform experiments, universal lathe type SUI 500 COMBI (TRENS, SK) was used. The mentioned lathe is determined for precision machining of shaft and flanged workpieces in a small and medium lot production. A standard steel C45 (STN 12 050) with diameter $\mathrm{D}=60 \mathrm{~mm}$ was selected as machined material. This steel is appropriate for production of less stressed shafts, gears, connecting rods, pins (spindles), etc.

Optimal mechanic values including ductility are achieved in hardened state and consequently in drawn state. For determination of cutting force components a piezoelectric dynamometer Kistler 9257B was used, which is able to measure independently three force values along the axis $\mathrm{x}, \mathrm{y}$ and z. As shows Figure 1., dynamometer is fixed on the fixture determined for measurement on the mentioned lathe where a fixture for tool grip is 


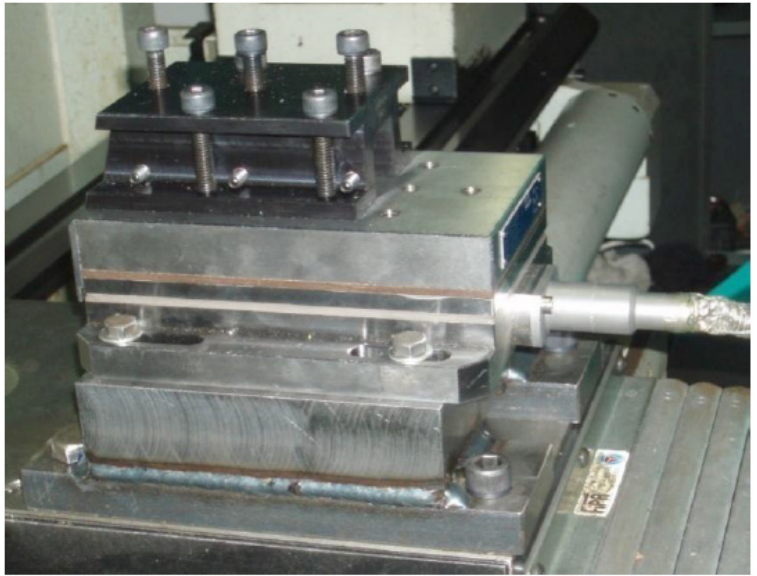

Fig. 1. Dynamometer Kistler 9257B

placed. Based on the measurement the force values $F_{f}, F_{p}, F_{c}$ were achieved and evaluated in experimental part.

For both experimental measurements cutting inserts were used - these are made of material NC 3020 (cemented carbide coated by CVD method), produced by company Korloy (ISO P15-P25). This material is intended for high speed machining of steels with recommended cutting speeds within the interval $170-370 \mathrm{~m} / \mathrm{min}$. This coat represents a combination of excellent wear resistance, fracture resistance and concurrently heat resistance.

For the first measurements a cutting insert type KORLOY WNMG 080408 - HM was applied (recommended depth of cut $a_{p}=1,0-5,0$ $\mathrm{mm}$ and feed $\mathrm{f}=0,1-0,5 \mathrm{~mm}$ ). Together with tool holder WWLNR 2525 - M08 they create a cross section of a cut layer illustrated in Fig. 2. In order to perform further measurements of cutting force components, a cutting insert KORLOY SNMG 120404 - GM was used, where recommended depth of cut $\mathrm{a}_{\mathrm{p}}=0,7-4,0 \mathrm{~mm}$ and feed

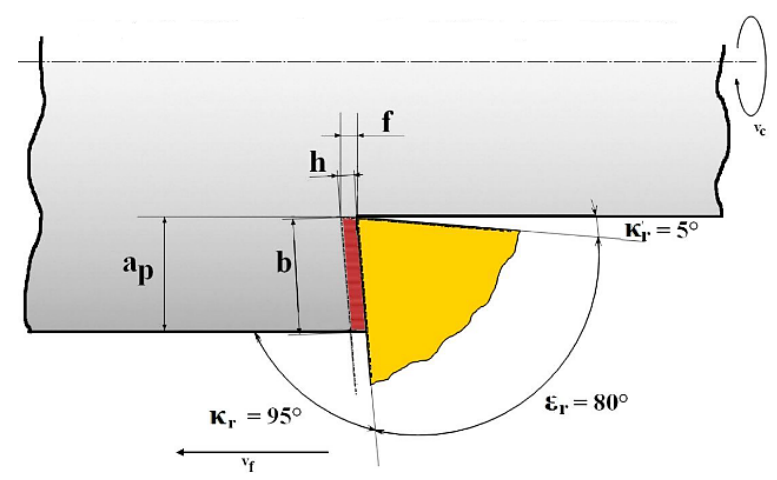

Fig. 2. Cross section of cut layer for tool WNMG $080408-\mathrm{HM} \mathrm{a}_{\mathrm{p}}=1,5 \mathrm{~mm}, \mathrm{f}=0,2 \mathrm{~mm}$

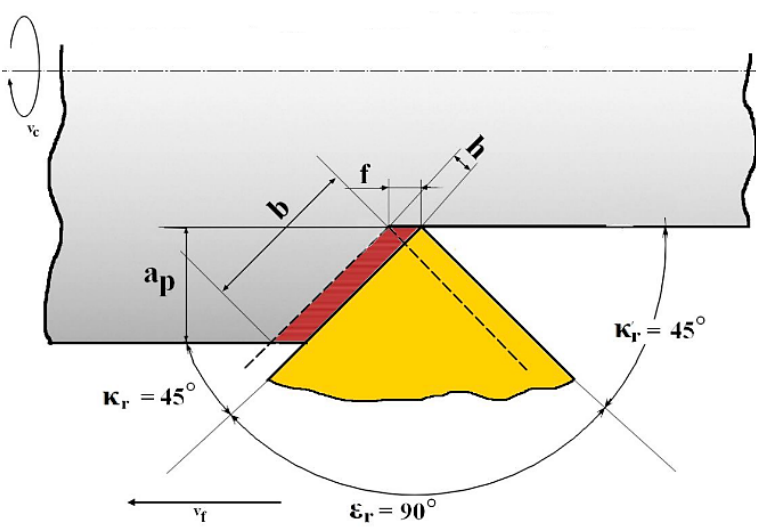

Fig. 3. Cross section of cut layer for tool SNMG $120404-\mathrm{GM} \mathrm{a}_{\mathrm{p}}=1,5 \mathrm{~mm}, \mathrm{f}=0,2 \mathrm{~mm}$

$\mathrm{f}=0,1-0,5 \mathrm{~mm}$. Analogous to previous measurement, tool holder PSSNR - M12 and cutting insert together create a certain geometry and cross section of cut layer as shown in Figure 3.

\section{EXPERIMENT PERFORMANCE}

The workpiece with diameter $\mathrm{D}=60 \mathrm{~mm}$ and length $300 \mathrm{~mm}$ was held in three jaw chuck and supported by rotating centre in tailstock. For both experiments the constant values depth of cut $\mathrm{a}_{\mathrm{p}}=1,5 \mathrm{~mm}$ and feed $\mathrm{f}=0,2 \mathrm{~mm}$ were set. The workpiece was longitudinal turned at cutting speeds $100,125,150,175,200,225$, $250 \mathrm{~m} \cdot \mathrm{min}^{-1}$. Subsequence of application of individual cutting speeds was random. New cutting inserts were used, which avoided the wear influence on cutting force components. The measurement of cutting forces was conducted in a short time period (during 10s) whereby also built-up-edge creation and its influence was eliminated. From achieved values measured by dynamometer a 5 -second time period was evaluated. Based on this time period, average values, as well as maximal and minimal values of respective components of cutting forces were determined.

\section{RESULTS OF THE EXPERIMENT}

Table 1 shows data from cutting force measurement using cutting insert WNMG-HM and Table 2 from measurement using cutting insert SNMG-GM with parameters mentioned in measurement process. 


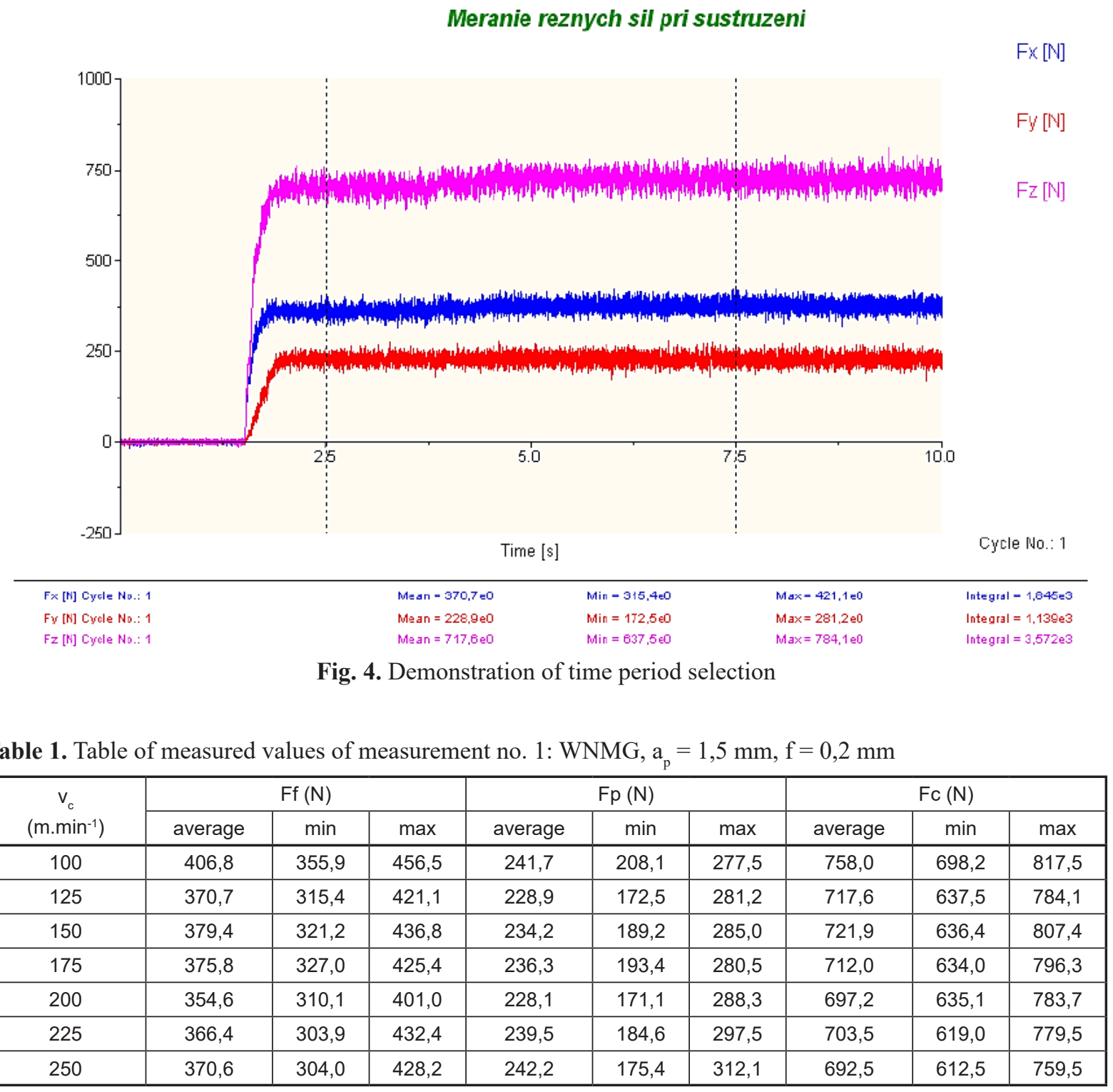

Table 2. Table of measured values of measurement no. 2: $\mathrm{SNMG}, \mathrm{a}_{\mathrm{p}}=1,5 \mathrm{~mm}, \mathrm{f}=0,2 \mathrm{~mm}$

\begin{tabular}{|c|c|c|c|c|c|c|c|c|c|}
\hline \multirow{2}{*}{$\begin{array}{c}\mathrm{v}_{\mathrm{c}} \\
\left(\mathrm{m} \cdot \mathrm{min}^{-1}\right)\end{array}$} & \multicolumn{3}{|c|}{$\mathrm{Ff}(\mathrm{N})$} & \multicolumn{3}{c|}{$\mathrm{Fp}(\mathrm{N})$} & \multicolumn{3}{c|}{$\mathrm{Fc}(\mathrm{N})$} \\
\cline { 2 - 10 } & average & $\min$ & $\max$ & average & $\min$ & $\max$ & average & $\min$ & $\max$ \\
\hline 100 & 420,8 & 394,7 & 452,9 & 517,6 & 474,4 & 564,0 & 820,4 & 764,5 & 873,2 \\
\hline 125 & 397,8 & 367,9 & 424,3 & 486,2 & 442,7 & 531,9 & 785,5 & 724,2 & 839,6 \\
\hline 150 & 400,4 & 362,5 & 442,0 & 486,0 & 430,1 & 523,0 & 769,6 & 706,7 & 842,9 \\
\hline 175 & 396,0 & 363,0 & 433,6 & 490,4 & 449,6 & 531,8 & 771,4 & 710,7 & 844,5 \\
\hline 200 & 383,2 & 345,5 & 415,9 & 478,1 & 432,6 & 526,4 & 757,3 & 682,4 & 836,9 \\
\hline 225 & 391,0 & 335,6 & 451,4 & 490,1 & 424,1 & 556,4 & 756,8 & 678,2 & 843,5 \\
\hline 250 & 390,8 & 340,1 & 442,7 & 491,6 & 410,5 & 568,6 & 749,6 & 684,3 & 812,5 \\
\hline
\end{tabular}

Resulting cutting force for both measurements at given cutting speeds was calculated from average values of respective cutting force components by vector sum according to the following relation:

$$
F=\sqrt{F_{f}^{2}+F_{p}^{2}+F_{c}^{2}}(N)
$$

Calculated values are stated in Table 3, graphic representation of these dependences show Figures 5 and 6. 
Table 3. Measured and calculated values of cutting forces

\begin{tabular}{|c|c|c|c|c|c|c|c|c|}
\hline \multirow{2}{*}{$\begin{array}{c}\mathrm{v}_{\mathrm{c}} \\
\left(\mathrm{m} \cdot \mathrm{min}^{-1}\right)\end{array}$} & \multicolumn{4}{|c|}{ WNMG } & \multicolumn{4}{|c|}{ SNMG } \\
\cline { 2 - 10 } & $\mathrm{Fp}(\mathrm{N})$ & $\mathrm{Ff}(\mathrm{N})$ & $\mathrm{Fc}(\mathrm{N})$ & $\mathrm{F}(\mathrm{N})$ & $\mathrm{Fp}(\mathrm{N})$ & $\mathrm{Ff}(\mathrm{N})$ & $\mathrm{Fc}(\mathrm{N})$ & $\mathrm{F}(\mathrm{N})$ \\
\hline 100 & 406,8 & 241,7 & 758 & 893,6 & 420,8 & 517,6 & 820,4 & 1057,4 \\
\hline 125 & 370,7 & 228,9 & 717,6 & 839,3 & 397,8 & 486,2 & 785,5 & 1005,8 \\
\hline 150 & 379,4 & 234,2 & 721,9 & 848,5 & 400,4 & 486,0 & 769,6 & 994,4 \\
\hline 175 & 375,8 & 236,3 & 712 & 839,1 & 396,0 & 490,4 & 771,4 & 996,2 \\
\hline 200 & 354,6 & 228,1 & 697,2 & 814,8 & 383,2 & 478,1 & 757,3 & 974,1 \\
\hline 225 & 366,4 & 239,5 & 703,5 & 828,6 & 391,0 & 490,1 & 756,8 & 982,8 \\
\hline 250 & 370,6 & 242,2 & 692,5 & 821,9 & 390,8 & 491,6 & 749,6 & 977,9 \\
\hline
\end{tabular}

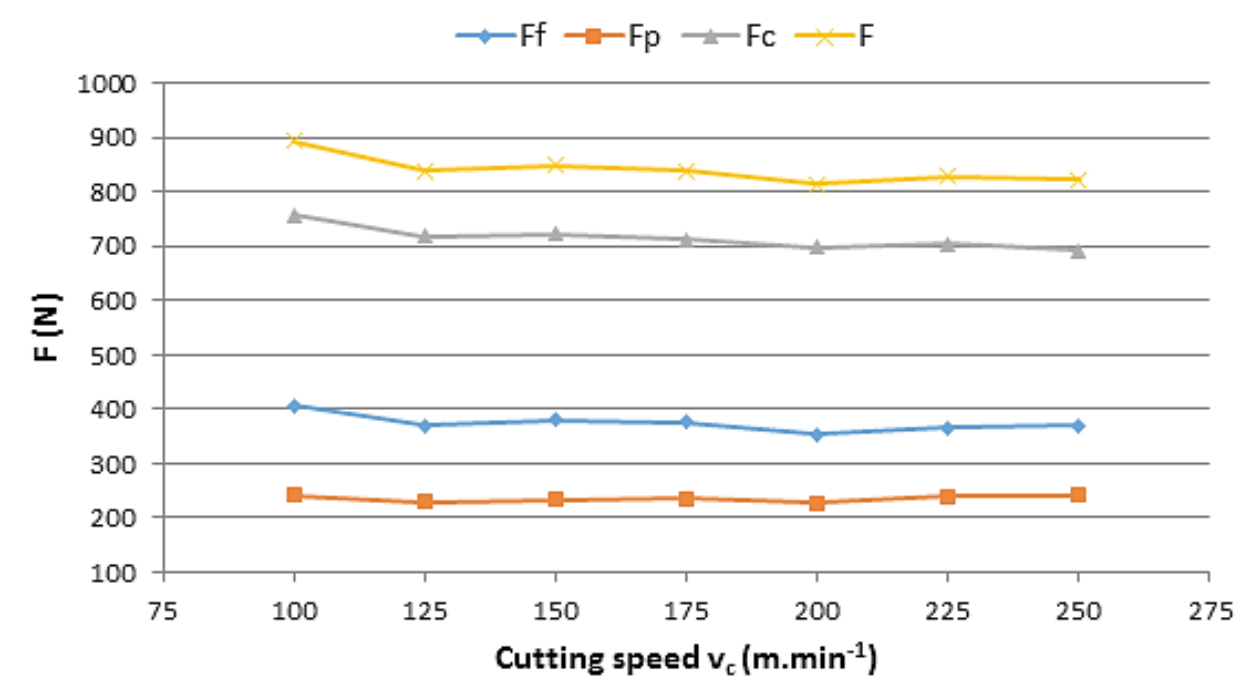

Fig. 5. Graphic representation of dependence of cutting force components on cutting speed for cutting insert WNMG
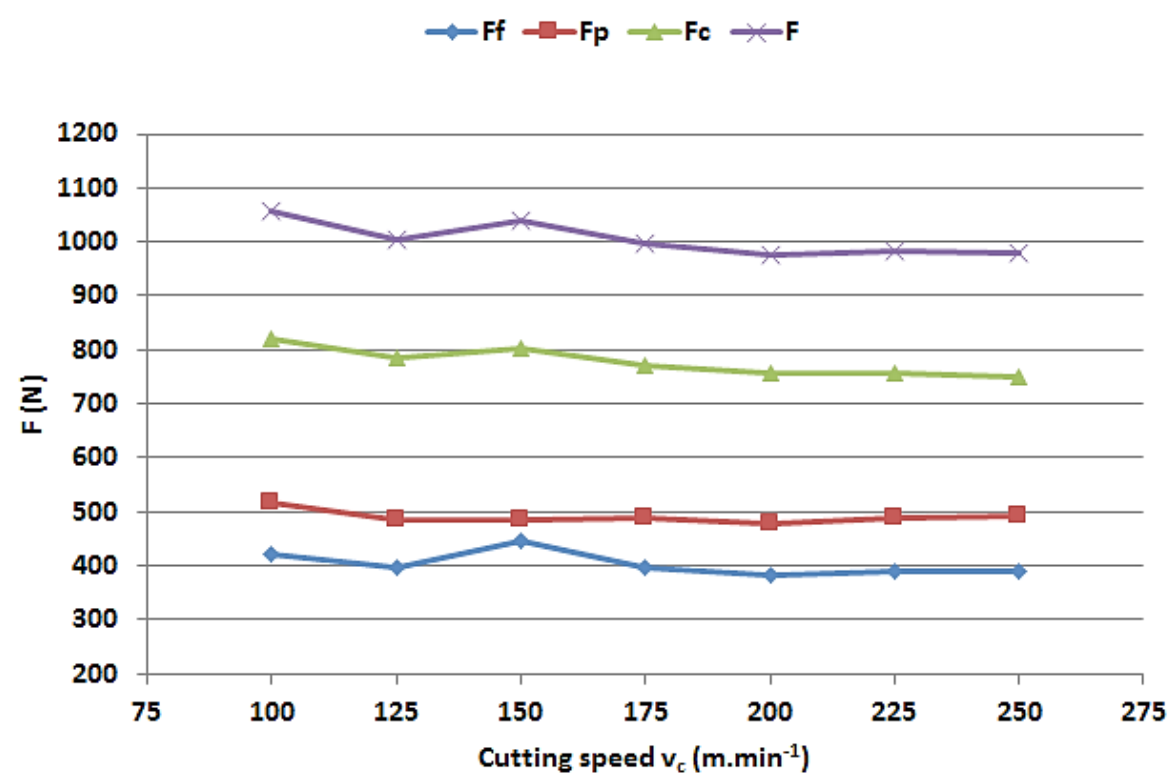

Fig. 6. Graphic representation of dependence of cutting force components on cutting speed for cutting insert SNMG 


\section{EXPERIMENT EVALUATION}

\section{Comparison of feed component of cutting force $\mathrm{Ff}$}

The feed force (axial cutting force) Ff affects along the direction of part axis. It is necessary to know its size with regard to calculation of feed machine mechanism. Resulting dependences and mutual comparison is shown in Figure 7.

As shown in graph, dependence tends to decrease at both measurements, which was anticipated on the basis of theoretical knowledge. The size of $\mathrm{Ff}$ force is bigger at measurement with cutting tip SNMG, this was caused by different tool geometry, especially by different size of end cutting edge angle $\kappa_{\mathrm{r}}$.

\section{Comparison of radial component of cutting force $\mathrm{Fp}$}

The transverse component of cutting force (radial, infeed) acts vertically on the rotation axis of the workpiece. From measured values it is evident that at both measurements the force values are not changing significantly and have a uniform trend to the whole extent of cutting speeds. For the cutting insert SNMG the cutting force value was approximately double (Fig. 8), this is caused by end cutting edge angle $\kappa_{\mathrm{r}}$. The choice of the

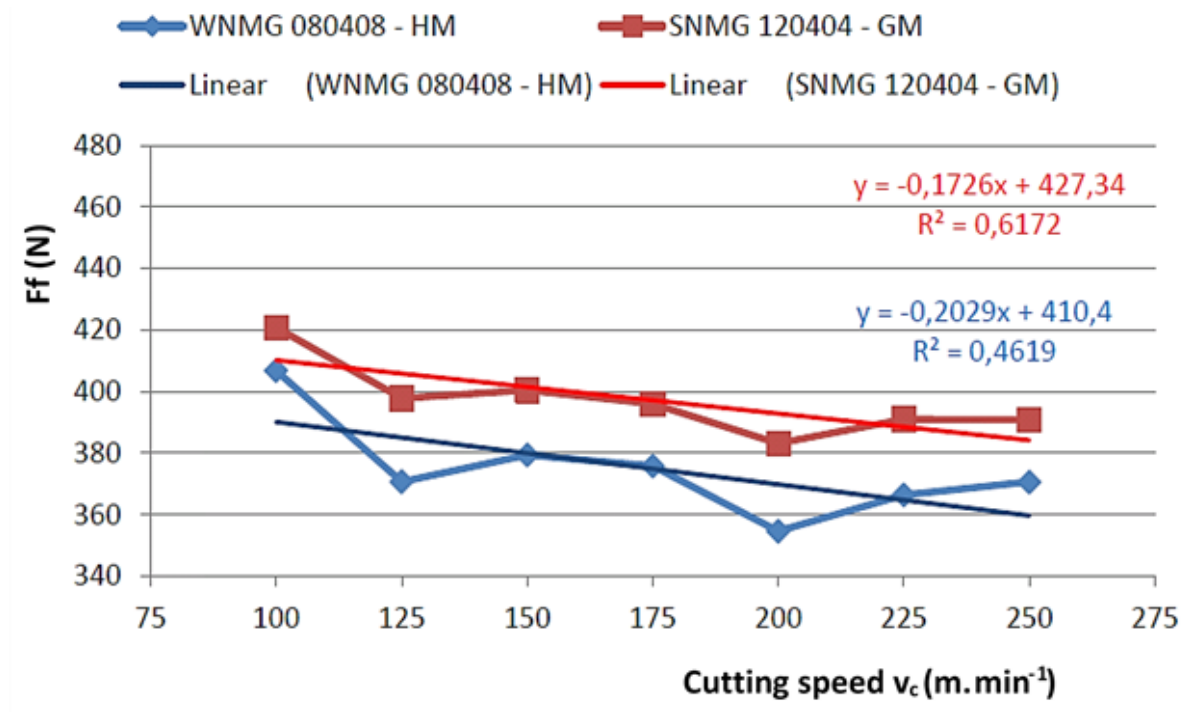

Fig. 7. Comparison of feed component of cutting force Ff

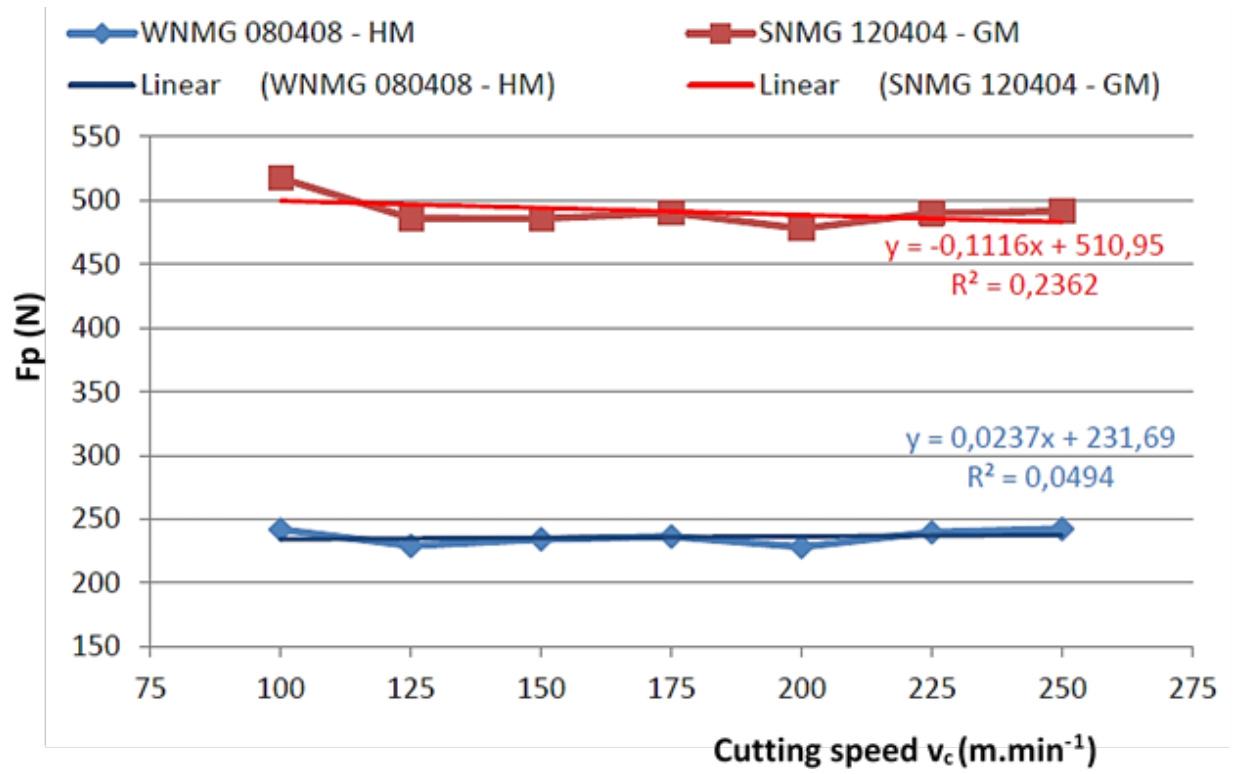

Fig. 8. Comparison of radial component of cutting force Fp 
mentioned angle values close to $90^{\circ}$ caused that the force $\mathrm{Fp}$ was reduced to a minimum (tool WNMG) and workpiece bending, as well.

\section{Comparison of tangential component of cutting force Fc}

The tangential or main cutting force Fc acts in the direction of cutting speed. [11]. Knowledge of its size is important for the calculation of main cutting motion performance, tool strength and strength of machine mechanism parts. [12]. It determines also rotational moment of spindle. Theory shows that as the end cutting edge angle increases, cutting force $\mathrm{Fc}$ decreases and its size relates also to cut width $\mathrm{b}[13,14]$. When the tool SNMG is applied, bigger cut width and also bigger cutting force are evident. This confirms the theoretical results [15]. Declining trend of cutting force depending on increasing cutting speed is obvious, as well. (Fig. 9)

\section{Comparison of resulting cutting force $F$}

The resulting cutting force includes the sum of all components and their impact on machined material through the cutting tool. As shown in Figure 10, it tends to decrease by increasing cutting speed, which results from the dependences of respective cutting force components.

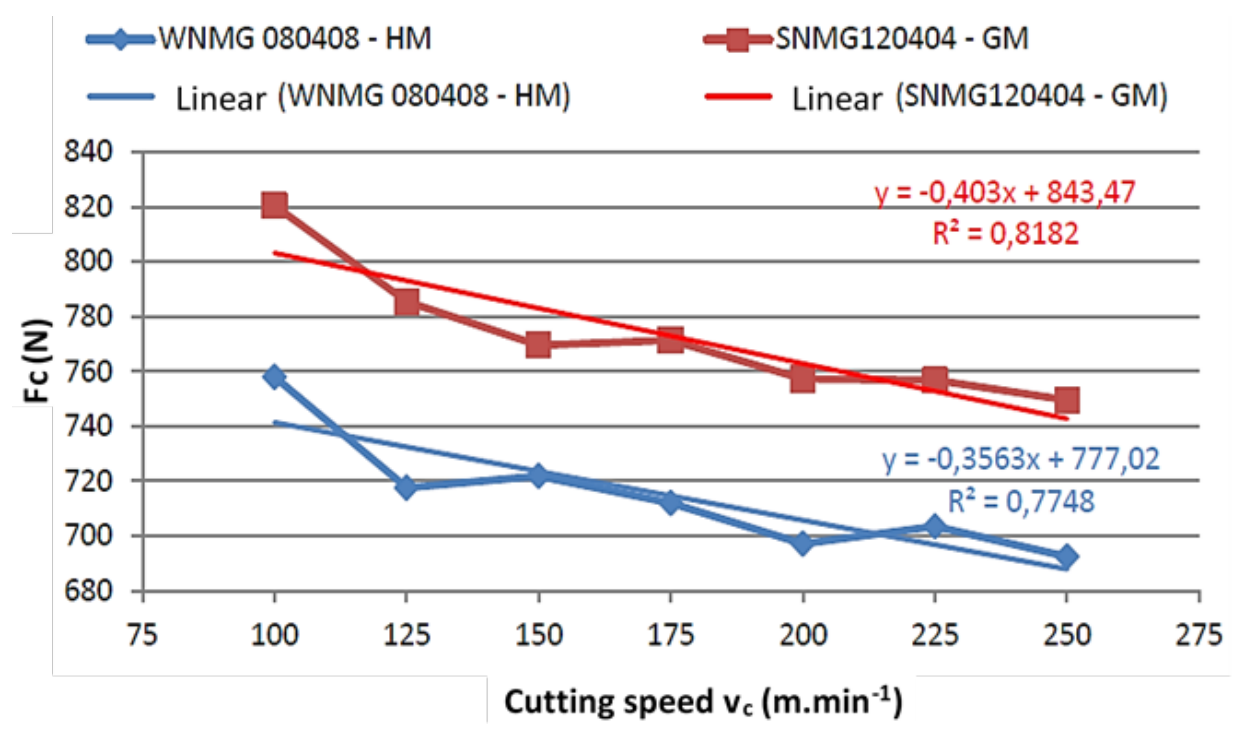

Fig. 9. Comparison of tangential component of cutting force $\mathrm{Fc}$

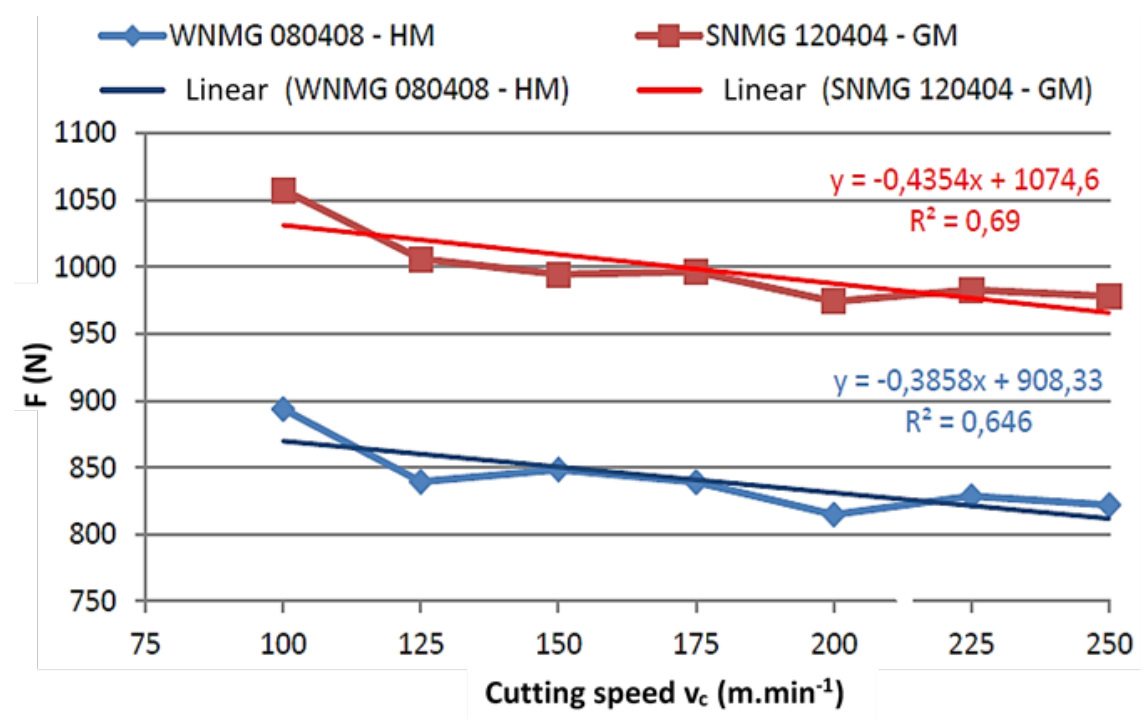

Fig. 10. Comparison of resulting cutting force $F$ 


\section{CONCLUSIONS}

Performed experimental work showed considerable influence of cutting wedge shape (geometry), chip formation, as well as cutting conditions (cutting speed in this case) on cutting forces and respective components of cutting forces. In all cases all components of cutting force and resulting cutting force decrease by increasing cutting speed. After the comparison of cuting wedge shape the results show that for cutting insert SNMG 120404 - GM the individual cutting force components as well as the resulting cutting force acquire higher values.

\section{REFERENCES}

1. Görög, A. Dynamic conditions for turning threads. In Progressive and innovative machining technology and manufacturing techniques 2012: Proceedings of VIII. International Scientific Conference held on the occasion of the 45th anniversary of the Department of Machining and Manufacturing Technology. 5.-7.9.2012, Papradno - Podjavorník, Žilina. Žilina: Žilinská univerzita, 2012, 54-55.

2. Janáč, A., Lipa, Z., Peterka, J. Theory of Machining. Bratislava: STU, 2006.

3. Vasilko, K., Murčinová, Z. Question of Optimal Cutting Speed for Machining by Conventional and Coated Cutting Tools. In: Manufacturing Technology, Vol. 15, 483-490.

4. Dubovská, R., Majerik, J. Experimental Investigation and Analysis of Cutting Forces When Machining X5CrNi18-10 Stainless Steel. In: In: Manufacturing Technology, Vol. 15, 322-329.

5. Vasilko, K., Mádl, J. Theory of Machining. Ústí nad Labem: Univerzita J.E. Purkyně, 2012.
6. Vasilko, K. Analytival Theory of Machining. Prešov: FVT, 2007.

7. Petřkovská, L., Brychta, J., Nováková, J. Aspects of High Speed Machining. Prešov: Manufacturing Engineering, FVT, 2008, 67-68.

8. Silva, R. L. et all. A note on the influence of cutting speed on cutting forces and surface finish during precision turning of aisi 1045 steel. In: Journal of engineering annals. Faculty of engineering Hunedoara. Vol. 6/2, 13-118.

9. Fang, N., Pai, P.S. \& Mosquea, S. Effect of tool edge wear on the cutting forces and vibrations in high-speed finish machining of Inconel 718: an experimental study and wavelet transform analysis. In: The International Journal of Advanced Manufacturing Technology, Vol. 52, 65-77.

10. Kamely, M.A., Noordin, M.Y.R. The impact of cutting tool materials on cutting force. World Academy of Science, Engineering and Technology (51) 2011, 903-906.

11. Sadílek, M., Čep, R., Sadílková, Z., Valíček, J., Petřkovská, L. Increasing tool life in turning with variable depth of cut. Materiali in tehnologije, Inštitut za kovinske materiale in tehnologije, 2013, 199-203.

12. Vasilko, K. Analysis of the impact of cutting speed on machining process. Manufacturing Engineering. Prešov: FVT, 2010, 9(1), 5-9.

13. Asthakov, V. P. Basic Definitions and Cutting Tool Geometry, Single Point Cutting Tools. In: Geometry of Single-point Turning Tools and Drills, 55-126.

14. Hruby, J., Schindlerova, V. - Rentka, J.: Degradation processes in the contact layers of forming tools. In. Manufacturing Technology, Volume 15, Issue 5, 1 November 2015, 836-842.

15. Neslušan, M., Turek, S., Brychta, J., Čep, R., Tabaček, M. Experimental Methods in Machining. Edis Žilina 2007, 345. 